\title{
Dedicated cardiac CZT SPECT is steadily moving to achieve its destiny
}

\author{
Doumit Daou, MD, PhD ${ }^{\mathrm{a}, \mathrm{b}}$ \\ a EA 7334 REMES, Université Paris-Diderot, Sorbonne Paris-Cité, Paris, France \\ b Nuclear Medicine Department, Cochin University Hospital, Paris Cedex 14, France
}

Received Jul 16, 2017; accepted Jul 17, 2017

doi:10.1007/s12350-017-1006-9

\section{See related article, pp. 443-452}

Conventional SPECT based on Anger gamma camera has been the cornerstone for the evaluation of myocardial perfusion imaging in nuclear cardiology. ${ }^{1}$ Over the last 30 years, successive important progresses in hardware, software, stress agents, and radiotracers built its clinical success. Without being exhaustive let us enumerate some of these important achievements: (1) the widespread availability of ${ }^{99 \mathrm{~m}}$ Tc-based myocardial perfusion imaging radiotracers in the early 1990s, (2) the commercialization of multi-head gamma cameras, (3) The widespread use of one-injection one-acquisition coupling of perfusion and function in the mid 1990s and (4) the availability of iterative reconstruction with resolution recovery and noise regularization in the mid 2000s. Noteworthy, the clinical value of SPECT/CT hybrid systems available since the early 2000s with its attenuation correction option is still debated but is slowly and steadily making its way to more widespread clinical use. Meanwhile, most centers are using the prone versus supine imaging as an alternative to attenuation correction, increasing unbearably the time of acquisition with conventional SPECT.

Noteworthily, the availability of very successful, completely automatic MPI SPECT processing software for the quantification of myocardial scar, extent and severity of ischemia and the quantification of left ventricular function has been one of the bases for its

Reprint requests: Doumit Daou, MD, PhD, Nuclear Medicine Department, Cochin University Hospital, 27 rue du Faubourg SaintJacques, 75679, Paris Cedex 14, France; doumit.daou@cch.aphp.fr J Nucl Cardiol 2019;26:453-5.

1071-3581/\$34.00

Copyright (C) 2017 American Society of Nuclear Cardiology. robustness and its widespread clinical success. And for nearly 30 years now, the value of SPECT MPI has been documented worldwide with a huge number of published studies realized on incalculable number of patients exploring nearly all kind of patients (obese, elderly, pacemakers, ...) and a wide variety of clinical situations. Noteworthy SPECT MPI is particularly suited to patients unable to exercise through the use of pharmacological stress with abundant literature on the subject validating its use. Its diagnostic value, its capacity to orient therapeutic options, its capacity to evaluate treatment efficacy, and its prognostic value are widely accepted.

Despite all its honorable achievements, conventional SPECT still faces some limitations that need to be overcome. Let us state the most important one, the underestimation of the extent of CAD as defined by anatomical imaging with a particular attention to patients with balanced 3-vessel disease and left main $\mathrm{CAD}^{2}$ And in this era of radiation reduction mania, the continuous search for radiation dose reduction is a priority. Besides, SPECT acquisition time reduction and overall exam time reduction are also important aspects that should continue to be addressed with conventional SPECT despite important achievements realized in this direction the last decade. ${ }^{1}$ And all these are to be achieved at reasonable costs with the worldwide known health care cost containment constraint.

To address these issues, in the late 2000s, nuclear cardiology has taken a new turn through the commercialization of dedicated cardiac CZT SPECT gamma cameras with the hope of surpassing all or some of the limitations of conventional SPECT. ${ }^{3}$ And in this sense, a hybrid CZT SPECT/CT system with attenuation correction is also commercialized in order to render MPI studies more quantitative.

These dedicated cardiac CZT SPECT gamma cameras are particularly characterized by better spatial resolution $(5 \mathrm{~mm})$, better sensitivity (5-7 times), and 
better energy resolution (2-times) as compared to conventional SPECT. Noteworthily, these characteristics have been accomplished through the combined use of CZT detector technology and of original multi-head designs that acquire simultaneously over an arc of $180^{\circ}$ in 3-D mode instead of the step-and-shoot principle used with conventional SPECT.

Dedicated cardiac CZT SPECT accomplished a tremendous reduction in radiation dose, in acquisition time and overall exam time. ${ }^{4-6}$ It improved image quality and patient comfort. Its diagnostic performances compare favorably with those of conventional SPECT. $\left.{ }^{7-9}\right]$ Some groups addressed with CZT SPECT some of the limitations encountered with conventional SPECT and reported a certain success (work in progress), i.e., coronary flow reserve to handle the underestimation of the extent CAD in patients with 3vessel and left main disease, respiratory motion handling to benefit from the system spatial resolution, dual cardiac and respiratory gating to address myocardial perfusion at end-diastolic phase. ${ }^{10-15}$

Meanwhile, to be widely clinically accepted and to compete with conventional SPECT for the realization of MPI studies, the performances of these new CZT SPECT imaging systems need to be at least equivalent to those of conventional SPECT. It should be able to provide all or most quantitative parameters provided by conventional SPECT particularly extent/severity of myocardial perfusion defects, regional and global LV function, and mechanical synchrony. And validation studies coming from diverse centers should be done on large number of patients in a wide variety of different clinical situations. This would reproduce one of the important characteristics that made the clinical acceptance and success of cardiac MPI realized with conventional SPECT, that is its clinical value, robustness and reproducibility in secondary and tertiary healthcare centers. In this sense, since the advent of dedicated cardiac CZT SPECT, published data are accumulating and exploring different clinical situations and different parameters. And in this issue of the journal, $\mathrm{Wu} \mathrm{D}$ et al. added useful data validating the use of CZT SPECT in a particular group of patients. ${ }^{16}$ The authors compare the value of CZT SPECT to conventional SPECT for the assessment of contractile function, mechanical synchrony, and myocardial scar in patients with heart failure. They demonstrate that CZT SPECT provided comparable data to C-SPECT for measuring LV scar, function and synchrony in this clinically important subgroup of population. The authors are to be congratulated for adding data to the clinical cardiology community. Such studies addressing particular subgroup of patients should be encouraged and will contribute undeniably to build up progressively the wide clinical acceptance and success of MPI using this new technology.

\section{Disclosure}

Author has nothing to disclose.

\section{References}

1. DePuey EG. Traditional gamma cameras are preferred. J Nucl Cardiol. 2016;23:795-802.

2. Berman DS, Kang X, Slomka PJ, Gerlach J, de Yang L, Hayes $\mathrm{SW}$, et al. Underestimation of extent of ischemia by gated SPECT myocardial perfusion imaging in patients with left main coronary artery disease. J Nucl Cardiol. 2007;14:521-8.

3. Bocher M, Blevis IM, Tsukerman L, Shrem Y, Kovalski G, Volokh L. A fast cardiac gamma camera with dynamic SPECT capabilities: design, system validation and future potential. Eur J Nucl Med Mol Imaging. 2010;37:1887-902.

4. Duvall WL, Sweeny JM, Croft LB, Ginsberg E, Guma KA, Henzlova MJ. Reduced stress dose with rapid acquisition CZT SPECT MPI in a non-obese clinical population: comparison to coronary angiography. J Nucl Cardiol. 2012;19:19-27.

5. Acampa W, Buechel RR, Gimelli A. Low dose in nuclear cardiology: state of the art in the era of new cadmium-zinc-telluride cameras. Eur Heart J Cardiovasc Imaging. 2016;17:591-5.

6. Agostini D, Marie PY, Ben-Haim S, Rouzet F, Songy B, Giordano A, Cardiovascular Committee of the European Association of Nuclear Medicine (EANM), et al. Performance of cardiac cadmium-zinc-telluride gamma camera imaging in coronary artery disease: a review from the cardiovascular committee of the European Association of Nuclear Medicine (EANM). Eur J Nucl Med Mol Imaging. 2016; doi:10.1007/s00259-016-3467-5.

7. Duvall WL, Sweeny JM, Croft LB, Barghash MH, Kulkarni NK, Guma KA, et al. Comparison of high efficiency CZT SPECT MPI to coronary angiography. J Nucl Cardiol. 2011;18:595-604.

8. Fiechter M, Ghadri JR, Kuest SM, Pazhenkottil AP, Wolfrum M, Nkoulou RN, et al. Nuclear myocardial perfusion imaging with a novel cadmium-zinc-telluride detector SPECT/CT device: first validation versus invasive coronary angiography. Eur J Nucl Med Mol Imaging. 2011;38:2025-30.

9. Miyagawa M, Nishiyama Y, Uetani T, Ogimoto A, Ikeda S, Ishimura $\mathrm{H}$, et al. Estimation of myocardial flow reserve utilizing an ultrafast cardiac SPECT: Comparison with coronary angiography, fractional flow reserve, and the SYNTAX score. Int J Cardiol. 2017;17:30184-5.

10. Daou D, Sabbah R, Coaguila C. Boulahdour. Feasibility of datadriven cardiac respiratory motion correction of myocardial perfusion CZT SPECT: a pilot study. J Nucl Cardiol. 2016;. doi: 10.1007/s12350-016-0493-4.

11. Ko CL, Wu YW, Cheng MF, Yen RF, Wu WC, Tzen KY. Datadriven respiratory motion tracking and compensation in CZT cameras: a comprehensive analysis of phantom and human images. J Nucl Cardiol. 2015;22:308-18.

12. Daou D, Sabbah R, Coaguila C, Boulahdour H. Applicability of data-driven respiratory motion correction to CZT SPECT myocardial perfusion imaging in the clinical setting: the birth of an old wish. J Nucl Cardiol. 2016; doi:10.1007/s12350-016-0633-x.

13. van Dijk JD, van Dalen JA, Mouden M, Ottervanger JP, Knollema $\mathrm{S}$, Slump $\mathrm{CH}$, et al. Value of automatic patient motion detection and correction in myocardial perfusion imaging using a CZTbased SPECT camera. J Nucl Cardiol. 2016;. doi:10.1007/s1 2350-016-0571-7.

14. Redgate S, Barber DC, Fenner JW, Al-Mohammad A, Taylor JC, Hanney MB, et al. A study to quantify the effect of patient motion and develop methods to detect and correct for motion during 
myocardial perfusion imaging on a CZT solid-state dedicated cardiac camera. J Nucl Cardiol. 2016;23:514-26.

15. Daou D, Sabbah R, Coaguila C, Boulahdour H. Impact of datadriven cardiac respiratory motion correction on the extent and severity of myocardial perfusion defects with free-breathing CZT SPECT. J Nucl Cardiol. 2017; doi:10.1007/s12350-017-0806-2.
16. Wu D, Zhang Z, Ma R, Guo F, Wang L, Fang W. Comparison of CZT SPECT and conventional SPECT for assessment of contractile function, mechanical synchrony and myocardial scar in patients with heart failure. J Nucl Cardiol. 2017;. doi: 10.1007/s12350-017-0952-6. 